\title{
Resilience, Identity Tension, Hope, Social Capital, and Psychological Stress During a Pandemic
}

\author{
John C. Sherblom ${ }^{1}$ (D) - Laura R. Umphrey ${ }^{2} \cdot$ Paulina Swiatkowski $^{2}$
}

Accepted: 20 October 2021 / Published online: 30 October 2021

C) Springer Nature Switzerland AG 2021

\begin{abstract}
The present study examines two conceptual approaches to defining resilience and the implications for its effect on psychological stress. One approach places resilience in the communication processes through which individuals and groups develop identity anchors, alternative logics, positive emotion, new normalcies, and communication networks during challenging times. The other approach describes the identity tension, hope, and social capital that develops in communication networks as relational attributes that create the contextual constraints and opportunities for that resilience. Regression analysis results demonstrate that both the communication processes and relational attributes of resilience affect psychological stress, but differently. The communication processes of establishing identity anchors, positive emotion, and communication networks predict the situational stress dimension. The relational attributes of personal-relational identity tension, hope, and weak-tie social capital predict the self-efficacy dimension. Both dimensions are important to understanding psychological stress. Hence, viewing resilience as a system of communication processes and relational attributes provides a fuller description of its relationship to psychological stress than either approach alone. This finding has implications for developing proactive strategies to manage the psychological stress of college students during the COVID-19 pandemic.
\end{abstract}

Keywords Resilience $\cdot$ Identity tension $\cdot$ Hope $\cdot$ Social capital $\cdot$ Psychological stress $\cdot$ COVID-19

Resilience is a complex phenomenon. It is defined and measured in multiple ways. In general, resilience describes "the ability to 'bounce back' or reintegrate after difficult life experiences [such as the]... looming possibilities of pandemics" (Buzzanell, 2010, pp. 1-2). "Pandemics, including COVID-19, are disasters with enormous impact" that test personal, family, group, organizational, community, and national levels of resilience (Masten \& Motti-Stefanidi 2020). A national survey finds that only about $40 \%$ of American adults consider themselves highly resilient within the context of the COVID-19 pandemic. With "60 percent of the

John C. Sherblom

john@maine.edu

Laura R. Umphrey

Laura.Umphrey@nau.edu

Paulina Swiatkowski

Paulina.Swiatkowski@nau.edu

1 Department of Communication and Journalism, University of Maine, Orono, ME, USA

2 School of Communication, Northern Arizona University, Flagstaff, AZ, USA population at risk... it is critical to understand how to build and maintain resilience" (Cigna, 2020, p. 4).

Researchers increasingly resist inward-looking perspectives as they recognize that resilience resides in the relational processes and attributes of contexts rather than in the traits of personality (Eley et al., 2013; Fitzgerald et al., 2021; Mahdiani \& Ungar, 2021). They differ, however, in which relational processes and attributes to include in defining resilience. This creates conceptual and measurement differences. Indeed, "for the last several decades... there has... been [an] ongoing debate about the definition, conceptualization, and measurement of resilience" (Mahdiani \& Ungar 2021, p. 147).

\section{A Communication Theory of Resilience}

Buzzanell (2010) locates resilience in the collective communication processes of families, groups, organizations, and communities. Resilience is "fundamentally grounded in [the] messages" collectively communicated among participants in a challenging situation. "Individuals and collectivities 
literally talk [resilience]... into existence" (Buzzanell, 2010, p. 9).

This perspective, which places resilience in the communication messages, is different from approaches that define it as influenced by relational attributes. For example, some relational approaches define resilience in the individual and group "redundancy, capacity for resourcefulness, effective communication, and capacity for self-organization in the face of extreme demands" (Doerfel et al., 2013). Other definitions locate resilience in the "affordances... demands... responsibilities [and]... realities" of the context (Palkovitz \& Fagan, 2021, p. 143). Still others define resilience as the "ability to find and use the individual, social and institutional resources (includinglhealth care) we need to cope" (Ungar \& Lustig, 2020, p. 1).

The present study compares these two perspectives that define resilience as either constituted in the communication processes or relational attributes. This distinction in defining resilience as communication processes or relational attributes is important. Conceptual distinctions lead to measurement differences. Together, conceptual and measurement distinctions affect understandings of what resilience is and how it affects an individual person's psychological stress.

We examine the implications of these two alternative perspectives on resilience for predicting the psychological stress of college students during the COVID-19 pandemic. Results indicate that communication processes and relational attributes both contribute to resilience, and both have implications for psychological stress. We begin with the communication theory of resilience and then discuss several influential relational attributes.

\section{Foregrounding Communication Processes of Resilience}

Many studies of resilience place communication in the background. Communication is treated as an antecedent or consequence of the relational context. It is conceived of as an asset or skill that can be learned by participants to adapt, solve problems, and become more resilient in times of challenging circumstances. Buzzanell and colleagues take an alternative view. They foreground a set of communication processes as defining resilience in individuals and groups (Lucas \& Buzzanell, 2012).

Their perspective is that communication is constitutive of the resilience experienced by individuals and groups responding to changes in social, economic, and historical conditions. This approach is based on the premise that participants "develop shared constructions of reality whereby they craft coherent narratives about the meanings of adversity and develop positive outlooks grounded in reality but promoting productive identities... adapt their organizational patterns to emphasize flexibility, connection, and relationships [and] engage in communication to clarify ambiguities, share feelings, find humor and comfort in family interactions and rituals, and collaborate in problem solving.... People as agentic beings... are situated in a complex tangle of specific historical, political, social, economic contexts for which they assign meaning to the choices they make and their positions in life" (Lucas \& Buzzanell, 2012, p. 192).

Buzzanell and colleagues define five processes of collective group communication that constitute resilience (Agarwal \& Buzzanell, 2015; Buzzanell, 2010; Lucas \& Buzzanell, 2012; Wu \& Buzzanell, 2013). These communication processes develop individual and group identity anchors, alternative logics, positive emotion, new normalcies, and communication networks during challenging times. These processes occur across the multiple interacting levels of individual, relational, family, organizational, community, and national systems (Houston \& Buzzanell, 2020).

An identity anchor is "a relatively enduring cluster of identity discourses upon which individuals and their familial, collegial, and/or community members rely when explaining who they are for themselves and in relation to each other" (Buzzanell, 2010, p. 4). It represents a collaborative communication process that realigns personal identities and group practices with the immediate needs of the context and moment in time. New identities arise through a collaborative discourse responding to a contextual challenge that is commonly perceived.

Alternative logics are constituted through a group's mundane talk. Participants reinterpret group policies, regulations, structures, and standard operating procedures. Together, they collaboratively reframe the challenges of the situation in ways that make sense of their lives and situation.

Emotion recognizes a communication process through which group members deliberately foreground the productive action of positive emotions, such as hope, while simultaneously acknowledging and legitimizing negative feelings, such as anger. Backgrounding these negative emotions does not mean suppressing them. This collective communication process acknowledges feelings of loss and injustice, but recognizes these as counterproductive to moving forward within the present challenging context. Foregrounding positive emotions acknowledges the whole emotional state, both positive and negative, and chooses to engage in the communication of hope.

A new normalcy means literally talking normalcy into being within the new, difficult situation. People, groups, families, communities, and nations all create a normalcy in their material realities through talk. This communication process makes sense of that reality and creates meaning in the new mundane regularities of life.

Communication networks build resilience as well. These networks are essential the resilience of families, groups, 
organizations, communities, and countries. They are developed and maintained through ongoing communication processes.

"Human resilience is constituted in and through communicative processes" (Buzzanell, 2010, p. 9). It is the collaborative effort of participants for whom "a new story, identity, mode of being, and way of behaving... is crafted" (Buzzanell, 2010, p. 9). Through a co-construction of identities, logics, emotions, situational framings, and networks, people reintegrate with each other, building a sense of resilience within the new realities of their everyday lives. They do this through their conversations, storytelling, group rituals, and ongoing communication.

\section{Empirical Evidence}

Buzzanell and colleagues develop an extensive program of research based on this communication theory, investigating resilience in relational, family, group, and community contexts (Buzzanell, 2010, 2018; Houston \& Buzzanell, 2018, 2020). These studies, performed over the past decade, examine resilient communication processes in disaster-relief responses to Hurricane Sandy, families experiencing financial hardship during an economic recession, and the experiences of Chinese immigrants beginning professional careers in the USA (Agarwal \& Buzzanell, 2015; Lucas \& Buzzanell, 2012; Wu \& Buzzanell, 2013). Additional research explores resilience in family, relational, organizational, community, and national contexts (Afifi, 2018; Bean, 2018; Buzzanell, 2018; Houston, 2018; Theiss, 2018). Other research examines resilience in group and organizational systems (Afifi et al., 2020; Haverfield \& Theiss, 2020; Venetis et al., 2020). They conclude that individuals, families, communities, and other groups that collectively participate in processes that develop identity anchors, alternative logics, positive emotion, new normalcies, and communication networks, and demonstrate greater resilience in adverse situations.

\section{Identity Tension, Hope, and Social Capital as Relational Attributes}

Other researchers treat the qualities of identity, hope, and networks as relational attributes that form the constraints, opportunities, and affordances of the context rather than the communication processes. This difference in perspective between treating resilience as constituted in the communication processes or as influenced by relational attributes of the context has both conceptual and measurement implications. We present three theory-based, empirically grounded perspectives on relational attributes that affect interpersonal communication.
First, Hecht (1993) describes identity as a personalrelational attribute. Identity is constituted through interpersonal conversation. However, Hecht and colleagues (Jung \& Hecht, 2004, 2008) measure the identity tension that affects that conversation by asking participants about their experience of the relationship rather than the communication process. Second, Synder (1994) develops a relational definition of hope. Multiple studies show that hope forms through relational communication processes. The measure of hope, however, is as a resultant way of thinking that affects relational communication. Third, Granovetter (1983) defines social capital as a resource that is available as a relational asset in communication networks. We describe each of these perspectives.

\section{Identity Tension}

Hecht (1993) defines identity as a personal-relational attribute that is enacted through conversation with family, friends, and community. Four interacting identity frames generate a personal-relational construction. These frames are the personal, enacted, relational, and communal (Jung \& Hecht, 2004).

The personal frame describes the meaning that people attribute to themselves, including personal motivations and expectations. The enacted frame recognizes the performance aspect of identity as individuals simultaneously express, interpret feedback, and internalize images of self in conversation with others, such as family, friends, work groups, and community members. The relational frame emerges through these conversations, as individuals define themselves within the relational expectations of family, friends, employers, and others. The communal frame contextualizes these expectations within the common goals, values, and attitudes of the community and culture (Hecht, 1993).

These personal, enacted, relational, and communal frames of identity are integrated through conversations with others. Within these conversations, individuals act out, modify, and internalize their identities. Hence, the communication processes of conversation both reflect and affect a person's conception of self.

Any inconsistencies that arise between how individuals see themselves and are seen by others create an identity tension. An inconsistency, for example, between the personal and enacted identity frames produces tension in the ability to freely express one's self in conversation. A personal-relational identity inconsistency creates tension in the relationship. Small amounts of tension are managed by temporarily suppressing one identity frame or another, but stressful life events generate greater challenges, with additional tension (Hecht, 1993; Jung \& Hecht, 2004).

Jung and Hecht (2008) examine the identity tensions experienced by Korean immigrants interacting with 
non-Koreans who ascribe stereotypical judgments to them that do not match the Korean individuals' self-images. Hecht and Maeda (2012) analyze the identity tensions of single Japanese women who live in a society that embraces a dominant ideology valuing marriage and family. Faulkner and Hecht (2011) discuss the identity tensions of lesbian-gaybisexual-transgender-questioning (LGBTQ) individuals of the Jewish faith. Other studies examine the identity tensions of transgender individuals living in a society that maintains a binary gender classification (Green-Hamann \& Sherblom, 2014, 2016; Nuru, 2014).

Buzzanell (2010, p. 4) defines the identity anchors of resilience as occurring in the "discourses upon which individuals and their familial, collegial, and/or community members rely when explaining who they are for themselves and in relation to each other." Hecht and colleagues analyze the identity tension that results from these communication processes as an influential relational attribute of the context. This distinction becomes important to measurement.

\section{Hope}

Snyder $(1994,2000)$ defines hope as a habitual way of thinking that develops through a life time of relational interactions. For example, a young child sitting in a room with a toy beyond reach may cry. When a caregiver is present the child can motion for assistance and the caregiver becomes a facilitator helping the child obtain the toy. Assisting or ignoring the child fosters or diminishes hopeful thinking (Snyder, 1994).

This definition conceptualizes hope as a combination of agency and pathways thinking. Agency thinking considers personal motivation to be a necessary part of hope. Pathways thinking consists in developing multiple, alternative relational strategies to achieve a goal. Habits of agency and pathways thinking develop over time in learned ways of communicating with others to accomplish personal-relational goals (Kemer \& Atik, 2012; Marques et al., 2011; Snyder, 1994, 2000).

Research studies show that hope is both communicated and modified over time (Feldman \& Dreher, 2012; Marques et al., 2011; Umphrey \& Sherblom, 2014; Valle et al., 2006; Yohani, 2008). The social communication processes of selfpresentation, interpersonal sensitivity, and relational listening are all involved in the development of hope (Umphrey \& Sherblom, 2017a, 2017b). In addition, hope reduces perceptions of being a relational burden to others, thwarted belongingness, and suicidal ideation (Umphrey et al., 2020).

Buzzanell (2010) recognizes resilience in the foregrounding of positive emotions such as hope. Snyder defines hope as a personal-relational attribute that can be learned and communicated. For Snyder, hope is both an antecedent and consequential way of thinking that is developed through relational communication rather than embedded within its processes.

\section{Social Capital}

"Social capital... has emerged as one of the most salient concepts in [the] social sciences" (Lin, 1999, p. 28). The term "social capital refers to the resources embedded in relationships and can vary in terms of bridging and bonding forms. Bridging refers to accessing diverse information gained through weak ties, while bonding refers to building up cohesion between communication partners that have invested the time necessary for deep trust. Bridging and bonding social capital are particularly salient in disaster contexts when both uncertainty and a need for trusted information are high" (Doerfel \& Haseki, 2015, p. 436).

Social capital is generated through networked relationships. It is inherently relational and can be transformative (Doerfel et al., 2010). Resilience resides in the ability to mobilize social capital, as a resource existing in the network, and develop new communication practices and relationships with networked partners to proactively respond to difficult situations, bolster recovery, and facilitate disaster relief (Doerfel et al., 2013).

Strong-tie networks provide the emotional bonds formed in families and close personal relationships. These strongtie networks provide individuals with social capital in a sense of similarity, mutual understanding, and emotional togetherness. Strong-tie network bonds increase feelings of trust, credibility, and reciprocity (Granovetter, 1983; GreenHamann \& Sherblom, 2014).

Weak-tie social capital develops in broader, more diverse network of acquaintances. These weak-tie relationships provide an informational bridging function to a variety of life experiences, multiple points of view, and diverse perspectives. "Individuals facing stressful situations, such as a lifethreatening disease, often find [that] weak-tie networks have unique and valuable advantages" (Wright \& Miller, 2010, p. 502). Weak-tie network participants gain access to important information sooner, providing a competitive advantage to act in a timelier manner (Monge \& Contractor, 2003). Access to this information can motivate, inspire, and provide new opportunities (Granovetter, 1983). The social capital of weak-tie networks reduces feelings of personal isolation, increases hope, facilitates positive health outcomes, reduces tendencies toward risky behavior, and provides opportunities for personal growth (Trepte et al., 2012).

Social capital resides in the network. It is a resource made available by the network. Social capital forms both antecedent and consequential relational contexts for the ongoing communication processes that occur within that network. Research studies show that social capital affects the resilience of personal and group responses to stressful life events 
(Doerfel et al., 2013; Green-Hamann \& Sherblom, 2014; Wright \& Miller, 2010).

\section{Implications}

The communication theory of resilience, articulated by Buzzanell and colleagues, measures a set of processes through which participants create a shared reality and collective response to a contextual adversity. Through these communication processes, participants craft coherent group narratives to promote positive identities and relationships, share feelings, clarify ambiguities, find humor, and collaborate on solving problems. Resilience describes this set of communication processes that emphasize flexibility, connection, and meaning creation within the group of people experiencing the contextual adversity (Lucas \& Buzzanell, 2012).

Identity tension, hope, and social capital, defined as relational attributes, describe contextual influences on resilience rather than communication processes. These relational attributes create affordances, challenges, and constraints on individual and group resilience. Identity tension challenges the resilience of personal-relational connection. Hope facilitates it. Social capital provides resources available for it.

Defining resilience as constituted in a set of communication processes or as influenced by relational attributes has implications for its relationship to other psychological constructs. Little empirical research develops the relationship between resilience and psychological stress. One reason may be found in the multiple conceptual definitions of resilience itself. The present study examines the implications of conceptualizing resilience either as constituted in the communication processes or as influenced by relational attributes present in the interpersonal context for analyzing its effects on psychological stress.

\section{Psychological Stress}

Cohen et al. (1983) describe and measure psychological stress. Since their initial study, numerous research projects have demonstrated the psychological stress experienced by individuals during such adverse situations as job loss, bereavement, illness, and physical injury (Nielsen et al., 2016; Reis et al., 2010; Roberti et al., 2006). Roberti et al. (2006) describe two underlying dimensions to this experience of psychological stress. The first dimension identifies the perception of a stressful situation. The second recognizes an individual's perceived self-efficacy for dealing with that situation. Reis et al. (2010) demonstrate these same two dimensions in a study of 793 participants in Brazil, and Nielsen et al. (2016) confirm these two dimensions in a study of 32,374 Danish participants.

\section{Research Question}

The present study compares two conceptual approaches to resilience. One treats resilience as a dynamic set of communication processes; the other as an entity influenced by the relational attributes of an interpersonal context. The study examines the implications of each approach for predicting the psychological stress experienced by college students during the COVID-19 pandemic.

Research Question: Does resilience as conceptualized in the processes of communication or as influenced by the relational attributes of identity tension, hope, and social capital predict the psychological stress of college students during the COVID-19 pandemic?

\section{Method}

\section{Psychological Stress of College Students during the COVID-19 Pandemic}

In the fall of 2020, the COVID-19 pandemic was resurgent, with daily case numbers rising, including among college students (Nixon et al., 2021). The pandemic created an upheaval in college student life. Students were asked to leave campus, adjust to new living circumstances, and switch from in-person to online learning in courses not originally designed for that delivery method. These changes increased student stress, anxiety, and fear. Students experienced a significantly negative impact on their mental health and well-being (Kecojevic et al., 2020).

College students living, learning, and social relationship situations are conducive to infectious disease transmission. Thousands of young people move into close proximity to study together, forming new interpersonal connections and social networks. Although they are mostly young and unlikely to experience the worst effects of a COVID-19 infection, students express concern for their own health and the potential for transmission to family members and the larger community (Nixon et al., 2021).

Son et al. (2020) report that $71 \%$ of the students in their study express increased levels of stress, anxiety, and depressive thoughts. Stressors include fear and worry for their own health and for their loved ones, difficulty concentrating, disruptions in sleep patterns, decreased social interactions due to physical distancing, and increased concerns for academic performance. Hamza et al. (2021) find that students with no preexisting mental health concerns show increases in sadness, anxiety, depression, psychological distress, mental health challenges, and feelings of burdensomeness to others. 


\section{The Present Sample}

The present sample contains the responses of college students attending a medium-sized university in the southwestern US obtained through an online survey conducted in October 2020. Prior to collecting the survey responses, researchers performed a series of interviews with a small sample of students to inquire about their concerns during the pandemic. Individual, semi-structured interviews conducted with students at this university indicate four main concerns.

First, students expressed a fear of getting sick. A vaccine was not yet available and students felt physically vulnerable. In addition to their own health, students expressed concern for family members. They were especially concerned for family members who were older or immunocompromised.

Second, the university had switched to a hybrid "flex" model of learning which allowed students the option to be in class or attend remotely via video conferencing. Most students decided to attend remotely, with only 1 or 2 students attending each class session in the classroom. The remote option, however, involved learning to cope with technological, social, and time-management challenges. Students expressed concerns with remote learning. They reported spending as much as $4-5$ hours a day trying to complete course assignments.

Third, students felt isolated from each other. They missed the social connection of sitting together with other students in a classroom. Mask mandates were in effect and socializing in groups outside of class was strongly discouraged. Most student gathering places were closed. Restaurants eventually opened up, but only for curbside pick-up. Movie theaters, sporting events, clubs, and bars all remained closed during this time period. Many students spent most of their time in their rooms, social distancing, alone, and feeling isolated. Many expressed loneliness. Students who previously had worked in the service industry experienced an additional worry and financial stress. Out of necessity, some students moved back home to live with family, which was not what they had hoped for during their college years.

Fourth, the university provided two pieces of software to track and manage the potential for a COVID-19 outbreak on campus. A phone app asked daily questions about physical health, temperature, and symptoms. A green light response at the end indicated that students could go about their daily business. A red light alert indicated the need to quarantine either because of potential symptoms or from having been into contact with someone who had tested positive. In addition, an online form allowed anyone to report a student perceived to be violating the university's COVID-19 policies. Students expressed concern for the consequences of being "turned in."

\section{Procedures}

Following institutional review board (IRB) approval, instructors of online courses were contacted and asked for permission to recruit their students as participants in an online survey. Subsequently, participants were recruited through an email that informed them of the nature of the study, explained their rights as participants, and provided a link to the online survey. Participant anonymity was maintained throughout the process. Those who completed the survey received extra credit through a "secret phrase" they could relay to their instructor. The survey took 15-20 min to complete. Each survey measure asked for a response on a 5-point Likert-type scale. Several items were reverse coded to reduce response bias.

\section{Survey Participants}

Two hundred twenty-eight students completed the survey. Their responses provide the data for the present analyses of resilience, identity tension, hope, social capital, and psychological stress. Demographic information was collected at the end of the survey. Of the participants who provided that information, 59 identify as male and 161 as female. Participant ages range from 18-62 with a mean age of $24.5(\mathrm{SD}=8.1)$. One hundred and fifty-one participants identify as Caucasian (70\%), 41 as Hispanic (17\%), 12 as Asian (5\%), 7 as American Indian (3\%), and 5 as African-American (2\%).

\section{Measurement Validity and Reliability}

We perform principal component analysis for each of the measures. These principal components analyses provide the comparisons of the present measures to those reported in the literature. Obtaining a component structure comparable to one reported in the literature establishes construct validity for the measure. Scale loadings on these components provide face validity for each of the measures. Cronbach's alpha analysis performed for the set of scales loading on each component provides the measure of reliability.

We perform principal component extraction and varimax rotation for each of the measures, using standard criteria for extracting and retaining the components. Extraction criteria include only retaining components that have an eigenvalue greater than 1.0 and account for at least 5\% of additional variance. Scale loading criteria include having a primary loading of at least 0.50 and a difference of at least 0.20 with any secondary loadings (Gorsuch, 1983). 


\section{Communication Processes of Resilience}

Resilience, conceptualized as constituted through a set of five communication processes, is measured as the participant's experience of those processes. Much of the research investigating resilience as constituted in communication processes uses interviews to inquire about participant experiences. Chernichky-Karcher et al. (2019) provide a comparable survey measure that asks cancer survivors and partners about their conversational talk. The present study uses similar survey questions to inquire about participant experiences during the COVID-19 pandemic.

For example, the present study analyzes responses to questions about identity anchors ("I feel like a different person..."), alternative logics ("I have found it relatively easy to follow the new rules..."), positive emotion ("I am easily able to focus on the positive..."), new normalcy ("my daily/ weekly routines have taken on a sense of normalcy..."), and communication networks ("I've experienced tough moments communicating with others...") to examine participant experiences during the pandemic. Responses to the questions of the current survey produce a component structure that is comparable to the one reported by Chernichky-Karcher et al. (2019). Scales load as expected on each of the five components. Table 1 shows these component loadings.

Component 1 represents the communication experience of self in identity anchors. Three scales load on this component. These include responses to the following: I feel like a different person, I don't feel like myself, and who I am has changed since the pandemic began. Component 1 produces an eigenvalue of 3.91 and accounts for $26.09 \%$ of the variance. The scales loading on component 1 generate a reliable index $(\alpha=0.79)$. Their mean provides the measure for identity anchors.

Component 2 represents alternative logics. Three scales load on component 2 . These scales include I have found it easy to adapt to the new rules, regulations for interacting with others, and ways to live my life during the pandemic. Component 2 has an eigenvalue of 2.73 and accounts for $18.22 \%$ of additional variance. The scales loading on component 2 produce a reliable index $(\alpha=0.75)$. Their mean provides the measure of alternative logics.

Component 3 represents resilience in emotions that focus on the positive while downplaying negative feelings. Four scales load on component 3 . They include I actively engage in thinking about how I want to respond, focus on the positive parts of life, put my anger and frustration aside, and experience moments of positive emotions such as hope, personal peace, and a sense of calm during the pandemic. Component 3 has an eigenvalue of 1.46, and accounts for $9.73 \%$ of additional variance. The component 3 scales produce a reliable index $(\alpha=0.73)$ and their mean is used to measure the resilience dimension of positive emotion.
Component 4 represents new normalcy. Three scales load on component 4 . These scales describe the experience of creating a new normal routine or difficulty in maintaining a normal routine during the pandemic. Component 4 has an eigenvalue of 1.19 , and accounts for $7.90 \%$ of additional variance. The component 4 scales produce a reliable index $(\alpha=0.70)$. Their mean is used to measure new normalcy.

Component 5 taps the dimension of communication networks. Two scales load on component 5. These scales elicit responses to the experience of having tough moments communicating with others and relationships that have been strained during the pandemic. Component 5 has an eigenvalue of 1.03 , and accounts for $6.91 \%$ of additional variance. Component 5 scales produce a reliable index $(\alpha=0.72)$. Their mean is used to measure communication networks.

\section{Identity Tension}

Identity tension exists as personal enacted and relational attributes of interpersonal conversational contexts. Personal-enacted tension measures how a participant feels about that interpersonal context through prompts such as "I feel that I can talk with other people in a way that is consistent with who I really am." Personal-relational measures feelings about the relationship with prompts like "I feel that other people see me as I see myself." Jung and Hecht (2004) report separate principal component analyses for personal-enacted and personal-relational identity tensions. The present study replicates their analyses.

The personal-enacted identity tension analysis produces a single component having an eigenvalue of 3.34 that accounts for $66.71 \%$ of the variance. The same five scales that Jung and Hecht (2004) report load on this component in the present study. These scales contain responses to statements indicating that I can be myself, speak truthfully, express the real me, and be consistent with who I really am when talking with other people. These scales produce a reliable index $(\alpha=0.87)$. Their mean provides the measure of personal-enacted identity tension (Table 2).

The personal-relational identity tension analysis produces a single component having an eigenvalue of 2.78 that accounts for $55.70 \%$ of the variance. The same five scales that Jung and Hecht (2004) report load on this component in the present study as well. These scales measure responses to statements such as other people see me as I see myself, have correct information about me, and like the same things about me that I like about myself. These scales produce a reliable index $(\alpha=0.79)$. Their mean provides the measure of personal-relational identity tension (Table 3). 
Table 1 Communication processes of resilience principal component analysis

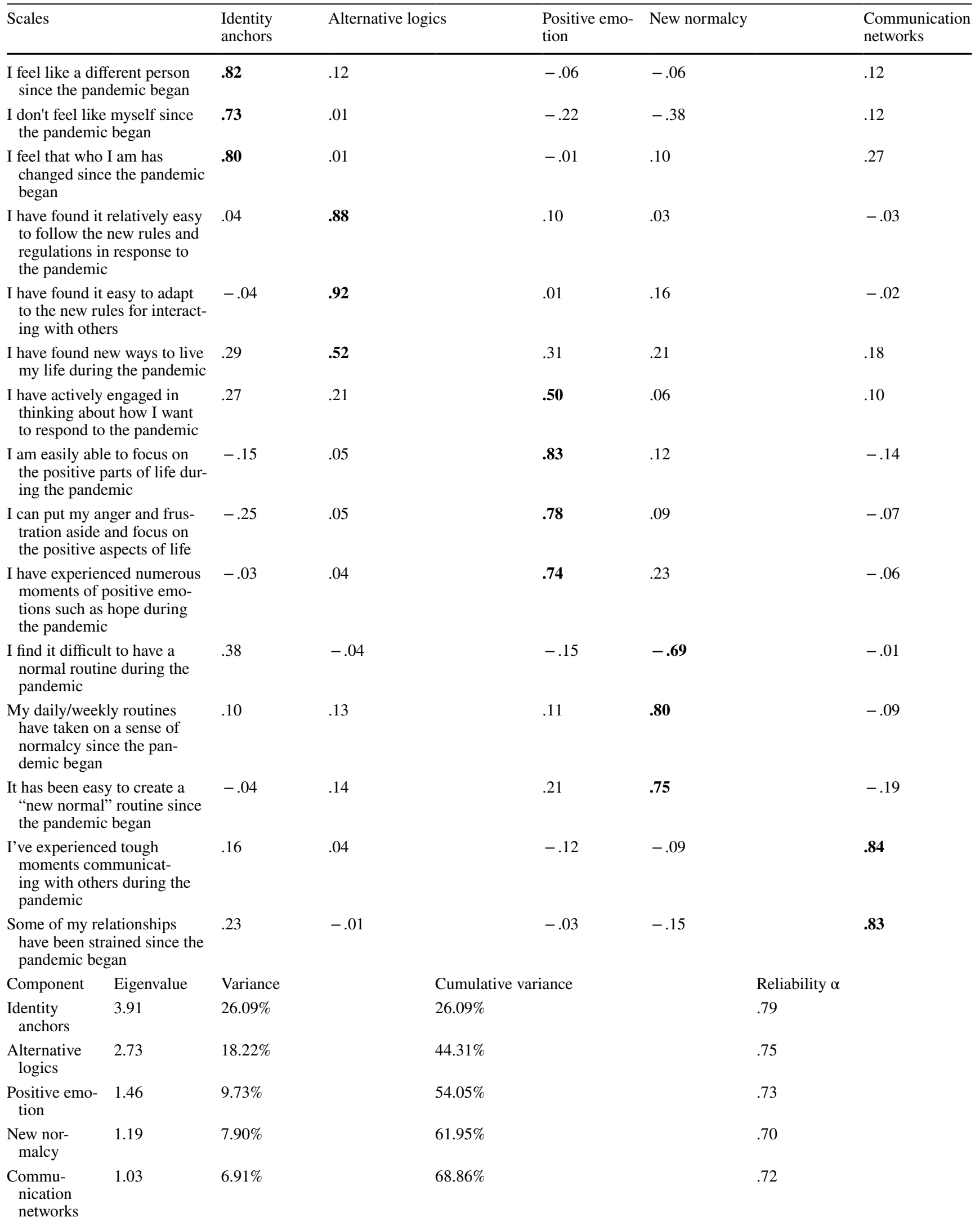


Table 2 Personal-enacted identity tension principal component analysis

\begin{tabular}{|c|c|c|}
\hline Scales & & Loadings \\
\hline When I talk with other people, they get to know the "real me." & & .77 \\
\hline I feel that I can talk with other people in a way that is consistent with who I really am & & .88 \\
\hline I feel that I can be myself when talking with other people & & .85 \\
\hline I speak truthfully to other people about myself & & .75 \\
\hline 1 freely express the real me in talking with other people & & .83 \\
\hline Variance $=66.71 \%$ & Reliability $\alpha=.87$ & \\
\hline
\end{tabular}

Table 3 Personal-relational identity tension principal component analysis

\begin{tabular}{|c|c|c|}
\hline Scales & & Loadings \\
\hline I feel that other people see me as I see myself & & .82 \\
\hline I agree with how other people describe me & & .79 \\
\hline I feel that other people have correct information about me & & .76 \\
\hline I feel that there is no difference between who I think I am and who other people think I am & & .66 \\
\hline Other people like the same things about me that I like about myself & & 69 \\
\hline Variance $=55.70 \%$ & Reliability $\alpha=.79$ & \\
\hline
\end{tabular}

\section{Hope}

Snyder (1994) provides an 8-item measure of hope. These eight items measure responses to statements indicating that I can think of many ways to get out of a jam, energetically pursue my goals, find lots of ways around any problem, find a way to solve the problem, and meet the goals that I set for myself. The principal component analysis in the present study produces loadings comparable to those reported in past studies (Hoy et al., 2013; Kemer \& Atik, 2012). The single component has an eigenvalue of 3.88 . It accounts for $48.52 \%$ of the variance. The eight items loading on this component produce a reliable index $(\alpha=0.84)$ and their mean is used to measure hope (Table 4).

\section{Social Capital}

Williams (2006) provides a measure of weak and strong tie social capital. The present analysis reproduces the twocomponent weak and strong tie social capital dimensions obtained by Williams. The present solution is comparable to the component structure obtained by Lee et al. (2018), as well.

Component 1 represents weak-tie social capital. Nine scales load on this component. These scales measure responses to statements indicating that talking with people makes me feel like I'm part of a larger community, connected to the bigger picture, interested in what people different from me are thinking, and that I am willing to spend time to support general community activities. Component 1 has an eigenvalue of 7.89 and accounts for $41.50 \%$ of the

Table 4 Hope principal component analysis

\begin{tabular}{ll}
\hline Scales & Loadings \\
\hline I can think of many ways to get out of a jam & .60 \\
I energetically pursue my goals & .75 \\
There are lots of ways around any problem & .67 \\
I can think of many ways to get the things in life that are most important to me & .76 \\
Even when others get discouraged, I know I can find a way to solve the problem & .75 \\
My past experiences have prepared me well for my future & .67 \\
I've been pretty successful in life & .65 \\
I meet the goals that I set for myself & Variance $=48.52 \%$ \\
Eigenvalue $=3.88$ & Reliability $\alpha=.84$ \\
\hline
\end{tabular}


variance. The scales loading on component 1 produce a reliable index $(\alpha=0.88)$. The mean of these scales provides the measure of weak-tie social capital.

Nine items load on the second component which represents strong-tie social capital. The scales loading on this component respond to statements indicating that there are people I can talk to, who I can turn to for advice, help me solve my problems, write good job references for me, and who would share their last dollar with me. This component has an eigenvalue of 1.95 and accounts for $10.28 \%$ of the variance. The scales loading on this component produce a reliable index $(\alpha=0.87)$. Their mean provides the measure of strong-tie social capital (Table 5).

\section{Psychological Stress}

Multiple principal component analyses reported in the literature establish two underlying dimensions to psychological stress. The present component analysis derives these two dimensions of psychological stress. The present two-component structure and scale loadings are comparable to those reported by Nielsen et al. (2016), Reis et al. (2010), and Roberti et al. (2006).

The first component reflects the cognitive load, negative feelings, and emotional impact that are perceived in a stressful life situation. It expresses the experience of an external life stressor and represents the level of stress experienced within the context of that situation. Six scale items load on this component which has an eigenvalue of 4.78 and accounts for $43.48 \%$ of the variance. These scales measure responses to feelings of being nervous, stressed, unable to control important aspects of life, not being able to cope, being emotionally angered, sensing that life is out of control, difficulties are piling up, and unexpected things are happening. These scales produce a reliable measure of the perceived situational stress $(\alpha=0.86)$. The mean of these responses is used to measure the situational stress.

The second component expresses an internal sense of self-efficacy, ability to cope, and capacity to respond to the stressful situation. This second component has an eigenvalue of 1.93 and accounts for an additional $17.50 \%$ of the variance. Five scales load on this second component. These scales describe perceived self-efficacy in a sense of confidence, coping effectiveness, and ability to handle personal problems, control irritations, be on top of things, and ultimately have things go your way. The scales loading on this component produce a reliable measure of self-efficacy $(\alpha=0.83)$. The mean of these scales provide the measure for self-efficacy (Table 6).
Table 5 Social capital principal component analysis

\begin{tabular}{|c|c|c|c|c|c|c|}
\hline \multicolumn{4}{|l|}{ Scales } & \multicolumn{2}{|l|}{ Weak tie } & Strong tie \\
\hline \multicolumn{4}{|c|}{ Talking with people makes me interested in different activities } & \multicolumn{2}{|l|}{.71} & .26 \\
\hline \multicolumn{4}{|c|}{ Talking with people makes me want to try new things } & \multicolumn{2}{|l|}{.77} & .22 \\
\hline \multicolumn{4}{|c|}{$\begin{array}{l}\text { Talking with people makes me interested in what people different } \\
\text { from me are thinking }\end{array}$} & \multicolumn{2}{|l|}{.66} & .18 \\
\hline \multicolumn{4}{|c|}{$\begin{array}{l}\text { Talking with people makes me curious about other places in the } \\
\text { world }\end{array}$} & \multicolumn{2}{|l|}{.76} & .12 \\
\hline \multicolumn{4}{|c|}{$\begin{array}{l}\text { Talking with people makes me feel like I'm part of a larger com- } \\
\text { munity }\end{array}$} & \multicolumn{2}{|l|}{.69} & .34 \\
\hline \multicolumn{4}{|c|}{ Talking with people makes me feel connected to the bigger picture } & \multicolumn{2}{|l|}{.70} & .30 \\
\hline \multicolumn{4}{|c|}{$\begin{array}{l}\text { Talking with people reminds me that everyone in the world is } \\
\text { connected }\end{array}$} & \multicolumn{2}{|l|}{.75} & .29 \\
\hline \multicolumn{4}{|c|}{ I am willing to spend time to support general community activities } & \multicolumn{2}{|l|}{.64} & .14 \\
\hline \multicolumn{4}{|c|}{ I like interacting with new people } & \multicolumn{2}{|l|}{.70} & .21 \\
\hline \multicolumn{4}{|c|}{ There are people I trust to help me solve my problems } & \multicolumn{2}{|l|}{.31} & .76 \\
\hline \multicolumn{4}{|c|}{$\begin{array}{l}\text { There is usually someone I can turn to for advice when making } \\
\text { important decisions }\end{array}$} & \multicolumn{2}{|l|}{.25} & .79 \\
\hline \multicolumn{4}{|c|}{ When I feel lonely, there are people I can talk to } & \multicolumn{2}{|l|}{.17} & .74 \\
\hline \multicolumn{4}{|c|}{$\begin{array}{l}\text { The people I interact with would put their reputation on the line } \\
\text { for me }\end{array}$} & \multicolumn{2}{|l|}{.16} & .62 \\
\hline \multicolumn{4}{|c|}{ The people I interact with would write good job references for me } & \multicolumn{2}{|l|}{.35} & .56 \\
\hline \multicolumn{4}{|c|}{ The people I interact with would share their last dollar with me } & \multicolumn{2}{|l|}{.19} & .69 \\
\hline \multicolumn{4}{|c|}{ The people I interact with would help me fight an injustice } & \multicolumn{2}{|l|}{.37} & .57 \\
\hline Component & Eigenvalue & Variance & Cumulative vari & ance & Reliability $\alpha$ & \\
\hline Weak tie & 7.89 & $41.50 \%$ & $41.50 \%$ & & .88 & \\
\hline strong tie & 1.95 & $10.28 \%$ & $51.78 \%$ & & .87 & \\
\hline
\end{tabular}




\section{Descriptive Statistics}

All responses to the survey questions are recorded on 5-point Likert-type scales. Some items are reverse coded to reduce response bias. The means and standard deviations generated using these scales are as follows: identity anchors ( mean $=2.34, \mathrm{SD}=1.03)$, alternative logics $($ mean $=2.22$, $\mathrm{SD}=0.95)$, positive emotion $($ mean $=2.29, \mathrm{SD}=0.85)$, new normalcy (mean $=3.01, \mathrm{SD}=0.96)$, communication networks (mean $=2.00, \mathrm{SD}=1.01)$, personal-enacted identity tension (mean $=2.20, \mathrm{SD}=0.86$ ), personal-relational identity tension $($ mean $=2.72, \mathrm{SD}=0.81)$, hope $($ mean $=2.11$, $\mathrm{SD}=0.63)$, weak-tie social capital $($ mean $=1.89, \mathrm{SD}=0.72)$, strong-tie social capital (mean $=1.90, \mathrm{SD}=0.69)$, stressful situation (mean $=2.39, \mathrm{SD}=0.83$ ), and self-efficacy (mean $=2.67, \mathrm{SD}=0.74)$.

\section{Correlations}

The correlations presented in Table 7 show an interesting pattern of relationships among the measures. As expected, the five dimensions of resilience as constituted in communication processes are, in general, moderately correlated. However, only the positive emotion dimension correlates with the relational attributes of identity tension, hope, and social capital. Positive emotion shows moderate correlations with personal-enacted $(r=0.23)$ and personal-relational $(r=0.28)$ identity tension, with hope $(r=0.54)$, and with weak-tie $(r=0.31)$ and strong-tie $(r=0.30)$ social capital. In addition, new normalcy shows a weak correlation with hope $(r=0.21)$. Only moderate correlations occur among the measures of identity tension, hope, and social capital, indicating that each measures a somewhat unique attribute of the relational context.

\section{Regression Results}

Two multiple regressions analyze the ability of identity anchors, alternative logics, positive emotion, new normalcy, communication networks, personal-enacted identity tension, personal-relational identity tension, hope, weak-tie social capital, and strong-tie social capital to predict the two orthogonal dimensions of psychological stress. The first regression analysis predicts situational stress $\left(R=0.67\right.$, adj. $R^{2}=0.42, F(10$, $209)=16.62, p<0.001, S E E=0.64)$. The second analysis predicts self-efficacy $\left(R=0.70\right.$, adj. $R^{2}=0.46, F(10$, $209)=19.95, p<0.001, S E E=0.54)$. Table 8 presents the regression results.
Table 6 Psychological stress principal component analysis

\begin{tabular}{|c|c|c|c|c|c|c|}
\hline \multicolumn{4}{|l|}{ Scales } & \multicolumn{2}{|c|}{ Situational stress } & Self-efficacy \\
\hline \multicolumn{4}{|c|}{$\begin{array}{l}\text { In the last month, how often have you felt that you were unable } \\
\text { to control important parts of your life? }\end{array}$} & \multicolumn{2}{|l|}{.68} & -.31 \\
\hline \multicolumn{4}{|c|}{$\begin{array}{l}\text { In the last month, how often have you felt nervous and } \\
\text { "stressed"? }\end{array}$} & \multicolumn{2}{|l|}{.79} & -.19 \\
\hline \multicolumn{4}{|c|}{$\begin{array}{l}\text { In the last month, how often have you found that you could not } \\
\text { cope with all the things that you had to do? }\end{array}$} & \multicolumn{2}{|l|}{.77} & -.20 \\
\hline \multicolumn{4}{|c|}{$\begin{array}{l}\text { In the last month, how often have you been angered because of } \\
\text { things that happened that were outside of your control? }\end{array}$} & \multicolumn{2}{|l|}{.74} & .01 \\
\hline \multicolumn{4}{|c|}{$\begin{array}{l}\text { In the last month, how often have you felt difficulties were piling } \\
\text { up so high that you could not overcome them? }\end{array}$} & \multicolumn{2}{|l|}{.76} & -.27 \\
\hline \multicolumn{4}{|c|}{$\begin{array}{l}\text { In the last month, how often have you been upset because of } \\
\text { something that happened unexpectedly? }\end{array}$} & \multicolumn{2}{|l|}{.75} & -.04 \\
\hline \multicolumn{4}{|c|}{$\begin{array}{l}\text { In the last month, how often have you felt that you were effec- } \\
\text { tively coping with important changes were occurring in your } \\
\text { life? }\end{array}$} & \multicolumn{2}{|l|}{.06} & .76 \\
\hline \multicolumn{4}{|c|}{$\begin{array}{l}\text { In the last month, how often have you felt confident about your } \\
\text { ability to handle your personal problems? }\end{array}$} & \multicolumn{2}{|l|}{-.25} & .76 \\
\hline \multicolumn{4}{|c|}{$\begin{array}{l}\text { In the last month, how often have you felt that things were going } \\
\text { your way? }\end{array}$} & \multicolumn{2}{|l|}{-.23} & .74 \\
\hline \multicolumn{4}{|c|}{$\begin{array}{l}\text { In the last month, how often have you been able to control irrita- } \\
\text { tions in your life? }\end{array}$} & \multicolumn{2}{|l|}{-.10} & .80 \\
\hline \multicolumn{4}{|c|}{$\begin{array}{l}\text { In the last month, how often have you felt that you were on top } \\
\text { of things? }\end{array}$} & \multicolumn{2}{|l|}{-.38} & \multirow[t]{4}{*}{.68} \\
\hline Component & Eigenvalue & Variance & Cumulative va & ariance & Reliabi & \\
\hline Situational stress & 4.78 & $43.48 \%$ & $43.48 \%$ & & .86 & \\
\hline Self-efficacy & 1.93 & $17.50 \%$ & $60.98 \%$ & & .83 & \\
\hline
\end{tabular}




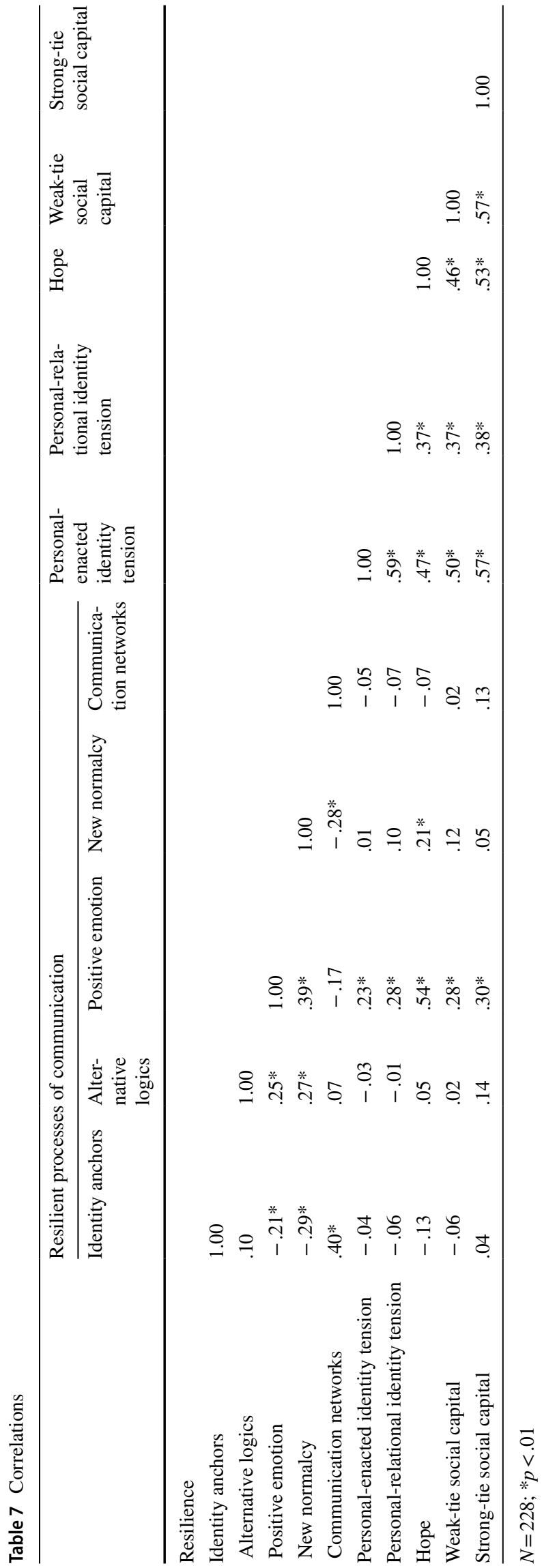

Results of the first regression analysis show that three of the communication processes constituting resilience predict situational stress. Identity anchors $(\beta=0.31, t=5.33$, $p<0.001)$, positive emotion $(\beta=-0.22, t=-3.23$, $p<0.001)$, and communication networks $(\beta=0.31$, $t=5.20, p<0.001)$ each contribute significantly to situational stress. Hope also contributes to situational stress $(\beta=-0.22, t=-3.04, p=0.003)$.

Results of the second regression analysis show that the relational attributes of personal-relational identity tension $(\beta=0.19, t=2.95, p<0.004)$, hope $(\beta=0.43, t=6.23$, $p<0.001)$, and weak-tie social capital $(\beta=-0.24$, $t=-3.36, p=0.001)$ predict self-efficacy. Positive emotion also contributes to this prediction of self-efficacy $(\beta=0.23, t=3.57, p<0.001)$.

\section{Discussion}

Resilience is a complex phenomenon. It can be conceptualized and measured in multiple ways. One research tradition places resilience in the communication processes of individual, family, group, organizational, and community talk. Other researchers describe the relational attributes of identity tension, hope, and social capital that form the constraints, opportunities, and affordances for that resilience.

The present study compares these communication process and relational attribute perspectives on resilience. It analyzes the effects of the communication processes and relational attributes of resilience in predicting the psychological stress of college students during the COVID-19 pandemic. Results indicate that both the communication processes and relational attributes of resilience predict psychological stress, but in different ways.

Masten and Motti-Stefanidi (2020, p. 95) call for "a unifying systems definition of resilience [that recognizes the]... adaptive capacities [of] interconnected networks and processes that co-evolved and may operate in concert." The present results suggest a systems perspective, recognizing both the communication processes and relational attributes of resilience, and provides a more complete description of the phenomenon and its relationship to psychological stress. "A system is the relation of structure and process, a unit that directs itself structurally in and through its own processes. A system, then, is an 'andness'. Unity is provided by the 'and' but not by any one element, structure, or relation" (Luhmann, 2013, p. 52).

The present results show the effects of both the communication processes and relational attributes of resilience in predicting psychological stress. Resilience, as measured in the communication processes of establishing identity anchors, positive emotion, and communication networks, predicts 
Table 8 Regression analysis results predicting psychological stress

\begin{tabular}{|c|c|c|c|c|c|c|}
\hline \multirow[t]{3}{*}{ Predictors } & \multicolumn{6}{|c|}{ Psychological stress } \\
\hline & \multicolumn{3}{|c|}{ Situational stress } & \multicolumn{3}{|c|}{ Self-efficacy } \\
\hline & Beta & $t$ & $p$ & Beta & $t$ & $p$ \\
\hline (Constant) & .00 & 6.94 & .000 & .00 & 3.10 & .002 \\
\hline \multicolumn{7}{|l|}{ Processes of resilience } \\
\hline Identity anchors & .31 & 5.33 & $<.001$ & -.07 & -1.16 & .246 \\
\hline Alternative logics & .02 & .37 & .714 & .10 & 1.90 & .058 \\
\hline Positive emotion & -.22 & -3.23 & .001 & .23 & 3.57 & $<.001$ \\
\hline New normalcy & .06 & .96 & .336 & .05 & .80 & .427 \\
\hline Communication networks & .31 & 5.20 & $<.001$ & -.06 & -1.04 & .301 \\
\hline \multicolumn{7}{|l|}{ Relational attributes } \\
\hline Personal-enacted identity tension & .06 & .73 & .466 & .00 & .06 & .952 \\
\hline Personal-relational identity tension & -.02 & -.27 & .787 & .19 & 2.95 & .004 \\
\hline Hope & -.22 & -3.04 & .003 & .43 & 6.23 & $<.001$ \\
\hline Weak-tie social capital & .05 & .61 & .543 & -.24 & -3.36 & .001 \\
\hline Strong-tie social capital & .01 & .14 & .887 & .10 & 1.58 & .116 \\
\hline
\end{tabular}

situational stress. The relational attributes of personalrelational identity tension, hope, and weak-tie social capital predict self-efficacy. Both are important dimensions of psychological stress. Viewing resilience as a system of both communication processes and relational attributes offers a fuller description of its relationship to these dimensions of psychological stress.

\section{Limitations}

The present study is limited by a single methodological approach, sample, and statistical analysis. The timing of the survey in October 2020, approximately 10 months after the public was first made aware of the pandemic but prior to an approved vaccine, contextualizes these findings. The present results offer a snap-shot of participant experiences at one point in time. Individual and collective experiences of resilience and psychological stress likely fluctuated over the months of the pandemic. These results, however, show the implications of resilience, as measured in communication processes and relational attributes, on the dimensions of psychological stress.

\section{Conclusion}

Recent research suggests a need to develop proactive strategies and preventive interventions to manage the psychological stress experienced by college students both during and after the pandemic (Kecojevic et al.,
2020; Son et al., 2020). The present results indicate that in order to manage both the situational and self-efficacy dimensions of psychological stress, intervention strategies should include both the communication processes and relational attributes of resilience. The communication processes that clarify, affirm, and reestablish identity anchors focus on the expression of positive emotions while backgrounding but not suppressing negative feelings, and develop communication networks that affect perceptions of situational stress. Self-efficacy appears more affected by the relational attributes of personal-relational identity tension, hope, and weak-tie social capital. The resilience process of communicating positive emotions and the relational attribute of hope influence both the situational and self-efficacy dimensions of psychological stress. Recognizing resilience in both the communication processes and relational attributes of individuals, families, groups, organizations, and communities provides a more complete understanding of its effects on the multiple dimensions of psychological stress.

Data Availability Dataset available at Sherblom, John, 2021, "Psychological Stress and Resilience," https://doi.org/10.7910/DVN/NTC6WF, Harvard Dataverse.

Code Availability Not applicable.

\section{Declarations}

Conflict of Interest The authors declare no competing interests. 


\section{References}

Afifi, T. D. (2018). Individual/relational resilience. Journal of Applied Communication Research, 6, 5-9. https://doi.org/10.1080/00909 882.2018.1426707

Afifi, T. D., Basinger, E. D., \& Kam, J. A. (2020). The extended theoretical model of communal coping: Understanding the properties and functionality of communal coping. Journal of Communication, 70, 424-446. https://doi.org/10.1093/joc/jqaa006

Agarwal, V., \& Buzzanell, P. M. (2015). Communicative re-construction of resilience labor: Identity/identification in disaster-relief workers. Journal of Applied Communication Research, 43, 408428. https://doi.org/10.1080/00909882.2015.1083602

Bean, H. (2018). National resilience. Journal of Applied Communication Research, 46, 23-25. https://doi.org/10.1080/00909882.2018. 1426709

Buzzanell, P. M. (2010). Resilience: Talking, resisting and imaging new normalcies into being. Journal of Communication, 60, 1-14. https://doi.org/10.1111/j.1460-2466.2010.01469.x

Buzzanell, P. M. (2018). Organizing resilience as adaptive-transformational tensions. Journal of Applied Communication Research, 46, 14-18. https://doi.org/10.1080/00909882.2018.1426711

Chernichky-Karcher, S. M., Venetis, M. K., \& Lillie, H. (2019). The dyadic communicative resilience scale (DCRS): Scale development, reliability, and validity. Supportive Care in Cancer, 27, 4555-4564. https://doi.org/10.1007/s00520-019-04763-8

Cigna (2020). Cigna resilience index: 2020 U.S. Report. Retrieved from: https://cignaresilience.com/.

Cohen, S., Kamarck, T., \& Mermelstein, R. (1983). A global measure of perceived stress. Journal of Health and Social Behavior, 24, 385-396. Retrieved from: https://www.jstor.org/stable/2136404

Doerfel, M. L., Chewning, L. V., \& Lai, C. (2013). The evolution of networks and the resilience of interorganizational relationships after disaster. Communication Monographs, 80, 533-559. https:// doi.org/10.1080/03637751.2013.828157

Doerfel M.L., \& Haseki, M. (2015). Networks, disrupted: Media use as an organizing mechanism for rebuilding. new media \& society, 17, 432-452. https://doi.org/10.1177/1461444813505362

Doerfel, M. L., Lai, C., \& Chewning, L. V. (2010). The evolutionary role of interorganizational communication: Modeling social capital in disaster contexts. Human Communication Research, 36 , 125-162. https://doi.org/10.1111/j.1468-2958.2010.01371.x

Eley, D. S., Cloninger, C. R., Walters, L., Laurence, C., Synnott, R., \& Wilkinson, D. (2013). The relationship between resilience and personality traits in doctors: Implications for enhancing wellbeing. Peer Journal, 19. Retrieved from: https://peerj.com/artic les/216/

Faulkner, S. L., \& Hecht, M. L. (2011). The negotiation of closetable identities: A narrative analysis of lesbian, gay, bisexual, transgendered queer Jewish identity. Journal of Social and Personal Relationships, 28(6), 829-847. https://doi.org/10.1177/0265407510 391338

Feldman, D. B., \& Dreher, D. E. (2012). Can hope be changed in 90 minutes? Testing the efficacy of a single-session goal-pursuit intervention for college students. Journal of Happiness Studies, 13, 745-759. https://doi.org/10.1007/s10902-011-9292-4

Fitzgerald, H. E., Robinson, L. R., Cabrera, N., \& Segal, L. (2021). Fathers and families: Risk and resilience. An Introduction. Adversity and Resilience Science, 2, 63-69. https://doi.org/10.1007/ s42844-021-00039-5

Gorsuch, R. L. (1983). Factor analysis. Erlbaum.

Granovetter, M. (1983). The strength of weak ties: A network theory revisited. Sociological Theory, 1, 201-233. Retrieved from: http:// www.jstor.org/stable/2776392
Green-Hamann, S., \& Sherblom, J. C. (2014). The influences of optimal matching and social capital on communicating support. Journal of Health Communication, 19(10), 1130-1144. https://doi.org/ 10.1080/10810730.2013.864734

Green-Hamann, S., \& Sherblom, J. C. (2016). Transgender transitioning: The influence of virtual on physical identities. The Electronic Journal of Communication, 26(4). Retrieved from: http://www. cios.org/ejcpublic/026/3/026344.html

Hamza, C. A., Ewing, L., Heath, N. L., \& Goldstein, A. L. (2021). When social isolation is nothing new: A longitudinal study on psychological distress during COVID-19 among university students with and without preexisting mental health concerns. Canadian Psychology, 62, 20-30. https://doi.org/10.1037/cap0000255

Haverfield, M. C., \& Theiss, J. A. (2020). Emotion regulation and resilience in parent-adolescent interactions among families of harmful versus non-harmful parental alcohol use. Journal of Applied Communication Research, 48, 26-48. https://doi.org/10.1080/00909 882.2019.1704827

Hecht, M. L. (1993). 2002 - A research odyssey: Toward the development of a communication theory of identity. Communication Monographs, 60, 76-82. https://doi.org/10.1080/0363775930 9376297

Hecht, M. L., \& Maeda, E. (2012). Identity search: Interpersonal relationships and relational identities of always-single Japanese women over time. Western Journal of Communication, 76(1), 44-64. https://doi.org/10.1080/10570314.2012.637539

Houston, J. B. (2018). Community resilience and communication: Dynamic interconnections between and among individuals, families, and organizations. Journal of Applied Communication Research, 46, 19-22. https://doi.org/10.1080/00909882.2018. 1426704

Houston, J. B., \& Buzzanell, P. M. (2018). Communication and resilience: Multilevel applications and insights - A Journal of Applied Communication Research forum. Journal of Applied Communication Research, 46, 1-4. https://doi.org/10.1080/00909882.2017. 1412086

Houston, J. B., \& Buzzanell, P. M. (2020). Communication and resilience: Introduction to the Journal of Applied Communication Research special issue. Journal of Applied Communication Research, 48, 1-4. https://doi.org/10.1080/00909882.2020.17119 56

Hoy, B. D., Suldo, S. M., \& Mendez, L. R. (2013). Links between parents' and children's levels of gratitude, life satisfaction, and hope. Journal of Happiness Studies, 14, 1343-1361. https://doi. org/10.1007/s10902-012-9386-7

Jung, E., \& Hecht, M. L. (2004). Elaborating the communication theory of identity: Identity gaps and communication outcomes. Communication Quarterly, 52(3), 265-283. https://doi.org/10.1080/ 01463370409370197

Jung, E., \& Hecht, M. L. (2008). Identity gaps and level of depression among Korean immigrants. Health Communication, 23(4), 313-325. https://doi.org/10.1080/10410230802229688

Kecojevic A., Basch C.H., Sullivan M., \& Davi, N.K. (2020). The impact of the COVID-19 epidemic on mental health of undergraduate students in New Jersey, cross-sectional study. PLOS ONE, 15https://doi.org/10.1371/journal.pone.0239696

Kemer, G., \& Atik, G. (2012). Hope and social support in high school students from urban and rural areas of Ankara, Turkey. Journal of Happiness Studies, 13, 901-911. https://doi.org/10.1007/ s10902-011-9297-Z

Lee, S., Chung, J. E., \& Park, N. (2018). Network environments and well-being: An examination of personal network structure, social capital, and perceived social support. Health Communication, 33, 22-31. https://doi.org/10.1080/10410236.2016.1242032 
Lin, N. (1999). Building a network theory of social capital. Connections, 22, 28-51. Retrieved 10/28/2021 from: http://faculty.washi ngton.edu/matsueda/courses/590/Readings/Lin/20Network/20The ory/201999.pdf

Lucas, K., \& Buzzanell, P. M. (2012). Memorable messages of hard times: Constructing short- and long-term resiliencies through family communication. Journal of Family Communication, 12, 189-208. https://doi.org/10.1080/15267431.2012.687196

Luhmann, N. (2013). Introduction to systems theory. Polity Press.

Mahdiani, H., \& Ungar, M. (2021). The dark side of resilience. Adversity and Resilience Science, 2, 147-155. https://doi.org/10.1007/ s42844-021-00031-z

Marques, S. C., Lopez, S. J., \& Pais-Ribeiro, J. L. (2011). "Building hope for the future": A program to foster strengths in middleschool students. Journal of Happiness Studies, 12, 139-152. https://doi.org/10.1007/s10902-009-9180-3

Masten, A. S., \& Motti-Stefanidi, F. (2020). Multisystem resilience for children and youth in disaster: Reflections in the context of COVID-19. Adversity and Resilience Science, 1, 95-106. https:// doi.org/10.1007/s42844-020-00010-w

Monge, P. R., \& Contractor, N. S. (2003). Theories of communication networks. Oxford University Press.

Nielsen, M. G., et al. (2016). The construct validity of the perceived stress scale. Journal of Psychosomatic Research, 84, 22-30. https://doi.org/10.1016/j.jpsychores.2016.03.009

Nixon, et al. (2021). Contacts and behaviours of university students during the COVID-19 pandemic at the start of the 2020/2021 academic year. Scientific Reports, 11, 11728. https://doi.org/10. 1038/s41598-021-91156-9

Nuru, A. K. (2014). Between layers: Understanding the communicative negotiation of conflicting identities by transgender individuals. Communication Studies, 65(3), 281-297. https://doi.org/10.1080/ 10510974.2013.833527

Palkovitz, R., \& Fagan, J. (2021). Faces of risk and resilience: Fathers and their families. Adversity and Resilience Science, 2, 141-146. https://doi.org/10.1007/s42844-021-00034-w

Reis, R. S., Hino, A. A. F., \& Rodriguez-Añez, C. R. (2010). Perceived stress scale reliability and validity study in Brazil. Journal of Health Psychology, 15(1), 107-114. https://doi.org/10.1177/ 1359105309346343

Roberti, J. W., Harrington, L. N., \& Storch, E. A. (2006). Further psychometric support for the 10-item version of the perceived stress scale. Journal of College Counseling, 9, 135-147. https://doi.org/ 10.1002/j.2161-1882.2006.tb00100.x

Snyder, C. R. (1994). The psychology of hope: You can get there from here. The Third Press.

Snyder, C. R. (2000). Handbook of hope: Theory, measures and applications. Academic Press.

Son, C., Hegde, S., Smith, A., Wang, X., \& Sasangohar, F. (2020). Effects of COVID-19 on college students' mental health in the United States: Interview survey study. Journal of Medical Internet Research, 22. Retrieved from: https://doi.org/10.2196/21279
Theiss, J. A. (2018). Family communication and resilience. Journal of Applied Communication Research, 46, 10-13. https://doi.org/10. 1080/00909882.2018.1426706

Trepte, S., Reinecke, L., \& Juechems, K. (2012). The social side of gaming: How playing online computer games creates online and offline social support. Computers in Human Behavior, 28, 832839. https://doi.org/10.1016/j.chb.2011.12.003

Umphrey, L. R., \& Sherblom, J. C. (2014). The relationship of hope to self-compassion, relational social skill, communication apprehension, and life satisfaction. International Journal of Wellbeing, 4(2), 1-18. https://doi.org/10.5502/ijw.v4i2.1

Umphrey, L. R., \& Sherblom, J. C. (2017a). The constitutive relationship of communication competence to self-compassion and hope. Communication Research Reports, 31, 22-32. https://doi.org/10. 1080/08824096.2017.1361395

Umphrey, L. R., \& Sherblom, J. C. (2017b). The constitutive relationship of listening to hope, emotional intelligence, stress, and life satisfaction. International Journal of Listening., 31, 1-25. https:// doi.org/10.1080/10904018.2017.1297237

Umphrey, L. R., Sherblom, J. C., \& Swiatkowski, P. (2020). Relationship of self-compassion, hope, and emotional control to perceived burdensomeness, thwarted belongingness, and suicidal ideation. Crisis, 1-7https://doi.org/10.1027/0227-5910/a000697

Ungar, M. \& Lustig, S. (2020). Building resilience: A framework for dealing with stress and adversity across the lifespan. Cigna-resilience-whitepaper-2020. https://cignaresilience.com/

Valle, M. F., Huebner, E. S., \& Suldo, S. M. (2006). An analysis of hope as a psychological strength. Journal of School Psychology, 44, 393-406. https://doi.org/10.1016/j.jsp.2006.03.005

Venetis, M. K., Chernichky-Karcher, S. M., \& Lillie, H. M. (2020). Communicating resilience: Predictors and outcomes of dyadic communication resilience processes among both cancer patients and cancer partners. Journal of Applied Communication Research, 48, 49-69. https://doi.org/10.1080/00909882.2019.1706098

Williams, D. (2006). On and off the 'net: Scales for social capital in an online era. Journal of Computer-Mediated Communication, 11, 593-628. https://doi.org/10.1111/j.1083-6101.2006.00029.x

Wright, K. B., \& Miller, C. H. (2010). A measure of weak-tie/strong-tie support network preference. Communication Monographs, 77(4), 500-517. https://doi.org/10.1080/03637751.2010.502538

Wu, M., \& Buzzanell, P. M. (2013). Liminalities at work: Chinese professionals' immigrant identity negotiations. China Media Research, 9, 15-26. Retrieved 11/6/2020 from: www.chinamedia research.net

Yohani, S. C. (2008). Creating an ecology of hope: Arts-based interventions with refugee children. Child Adolescent Social Work Journal, 25, 309-323. https://doi.org/10.1007/s10560-008-0129-x 